\title{
LONG-TERM DYNAMIC LOADING IMPROVES THE MECHANICAL PROPERTIES OF CHONDROGENIC MESENCHYMAL STEM CELL-LADEN HYDROGELS
}

\author{
Alice H. Huang ${ }^{1,2}$, Megan J. Farrell ${ }^{1,2}$, Minwook Kim ${ }^{1}$, and Robert L. Mauck ${ }^{1,2, *}$ \\ ${ }^{1}$ McKay Orthopaedic Research Laboratory, Department of Orthopaedic Surgery, ${ }^{2}$ Department of Bioengineering, \\ University of Pennsylvania, Philadelphia, PA 19104, USA
}

\begin{abstract}
Mesenchymal stem cells (MSCs) are an attractive cell source for cartilage tissue engineering given their ability to undergo chondrogenesis in $3 \mathrm{D}$ culture systems. Mechanical forces play an important role in regulating both cartilage development and MSC chondrogenic gene expression, however, mechanical stimulation has yet to enhance the mechanical properties of engineered constructs. In this study, we applied long-term dynamic compression to MSC-seeded constructs and assessed whether varying pre-culture duration, loading regimens and inclusion of TGF- $\beta 3$ during loading would influence functional outcomes and these phenotypic transitions. Loading initiated before chondrogenesis decreased functional maturation, although chondrogenic gene expression increased. In contrast, loading initiated after chondrogenesis and matrix elaboration further improved the mechanical properties of MSC-based constructs, but only when TGF$\beta 3$ levels were maintained and under specific loading parameters. Although matrix quantity was not affected by dynamic compression, matrix distribution, assessed histologically and by FT-IRIS analysis, was significantly improved on the micro- (pericellular) and macro- (construct expanse) scales. Further, whole genome expression profiling revealed marked shifts in the molecular topography with dynamic loading. These results demonstrate, for the first time, that dynamic compressive loading initiated after a sufficient period of chondroinduction and with sustained TGF- $\beta$ exposure enhances matrix distribution and the mechanical properties of MSCseeded constructs.
\end{abstract}

Keywords: Cartilage, tissue engineering, mesenchymal stem cells, chondrogenesis, mechanical stimulation.

\author{
*Address for correspondence: \\ Robert L. Mauck \\ McKay Orthopaedic Research Laboratory \\ Department of Orthopaedic Surgery \\ University of Pennsylvania \\ $36^{\text {th }}$ Street and Hamilton Walk \\ Philadelphia, PA 19104, USA
}

Telephone Number: (215) 898-3294

FAX Number: (215) 573-2133

E-mail: lemauck@mail.med.upenn.edu

\section{Introduction}

Adult bone marrow derived mesenchymal stem cells (MSCs) are a multipotent cell type capable of differentiation along a number of tissue-specific pathways (Pittenger et al., 1999). As MSCs are also easy to isolate and self-renewing, they have emerged as an attractive cell type for engineering tissue replacements. The ability of MSCs to undergo chondrogenesis and take on a 'chondrocyte-like' phenotype renders these cells especially useful for cartilage engineering (Pittenger et al., 1999; Johnstone et al., 1998; Prockop, 1997), and numerous studies have demonstrated successful induction of chondrogenesis in a variety of biomaterials (Chung and Burdick, 2009; Erickson et al., 2009a; Li et al., 2005; Hofmann et al., 2006; Huang et al., 2009a). In the presence of TGF- $\beta$ superfamily members, MSCs in 3D culture express cartilage-specific markers and deposit a extracellular matrix (ECM) rich in proteoglycans and collagen type II (Erickson et al., 2009a; Erickson et al., 2009 b). However, despite their initial promise, MSCbased constructs for cartilage regeneration have yet to achieve functional properties approaching that of the native tissue, or even that of chondrocyte-based constructs cultured identically (Huang et al., 2009b; Mauck et al., 2006). These limitations in functional chondrogenesis are not due to insufficient cell number within the constructs (Huang et al., 2009b; Kavalkovich et al., 2002), but rather, may be due to an intrinsic limitation in TGF- $\beta$ mediated chondrogenesis, in the absence of additional stimuli. Given the mechanically demanding environment of articular cartilage, the ability of MSC-based constructs to function within this environment is an important consideration and will directly affect clinical success.

Mechanical stimulation may be one strategy for optimizing chondrogenesis and overcoming these functional limitations. The rationale for this strategy is self evident; mechanical loading plays a vital role in the development, remodeling and maintenance of normal articular cartilage. During development, inhibition of muscle contraction and forces acting on skeletal elements results in abnormal joint formation (Mikic et al., 2004; Mikic et al., 2000). After birth, loading-induced remodeling of articular cartilage leads to dramatic changes in tissue structure (particularly of the collagen network) and increases in mechanical properties; in the absence of loading, this remodeling is not observed (Williamson et al., 2003a; Williamson et al., 2001; Williamson et al., 2003 b). In addition, normal joint loading has also been implicated in the maintenance of the chondrogenic phenotype of articular chondrocytes within cartilage (Chen et al., 2008). 
For cartilage tissue engineering, dynamic compression has proven especially effective in improving the functional properties of chondrocyte-seeded constructs (Mauck et al., 2000; Mauck et al., 2003a; Lima et al., 2006). While less is known regarding the mechanoresponsivity of MSCbased constructs, recent work with MSCs and related cell types show that dynamic compression modulates the chondrogenic phenotype of these cells (Elder, 2002; Elder et al., 2001; Elder et al., 2000). In general, loading of human or rabbit MSCs increases expression of aggrecan and collagen type II (Angele et al., 2004; Huang et al., 2004 ), and is mediated by induction of the TGF- $\beta$ signaling pathway (Huang et al., 2005). The presence/absence of TGF- $\beta$ also dictates the response of MSCs to compressive loading. Loading in the absence of TGF- $\beta$ improves proteoglycan synthesis levels of equine MSCs relative to free swelling controls while in cultures loaded in the presence of TGF- $\beta$, matrix synthesis levels diminish (Kisiday et al., 2009). Taken together, these findings suggest that dynamic compression modulates MSC chondrogenic differentiation and that the presence/absence of TGF- $\beta$ influences this process.

While promising, the majority of the studies noted above were limited to short-term loading durations and focused on changes in gene expression and instantaneous measures of ECM synthesis. These studies have not established a link between these transient events and functional outcomes related to matrix accumulation and mechanical properties of the forming tissue. Indeed, repeated exposure to physical stimuli is often required for transient perturbations in ECM synthesis to culminate in changes in functional properties (Angele et al., 2003). In one recent study, dynamic compression (initiated immediately after porcine MSC encapsulation in agarose) was carried out over 42 days in the presence of TGF- $\beta$. Findings from this study showed a marked reduction in the mechanical properties of loaded constructs compared to free-swelling controls (Thorpe et al., 2008). In this previous work, loading was initiated before chondrogenesis had developed or deposition of local ECM had occurred, however, others have suggested that these initial phenotypic transitions may regulate MSC response to physical signals. For example, Mouw et al. showed that a single application of dynamic compression improved both collagen type II and aggrecan expression when bovine MSC-seeded constructs were pre-cultured in TGF- $\beta 1$ containing media for longer culture durations (Mouw et al., 2007). Similarly, Terraciano et al. demonstrated that human embryonic stem cells in $3 \mathrm{D}$ culture responded adversely to compressive loading in the absence of TGF$\beta$; but responded positively when loading was initiated after a period of chondrogenic pre-differentiation (Terraciano et al., 2007).

Collectively, these foundational studies on MSC mechanobiology suggest that dynamic compressive loading can modulate MSC chondrogenesis, though it is important to consider species differences when interpreting these findings as a number of these studies utilized MSCs derived from various species. These same studies also indicate that loading-mediated improvements in functional maturation of MSC-seeded constructs with dynamic loading may require the establishment of a chondrogenic phenotype before exposure to mechanical perturbation. To test this hypothesis, we applied long-term dynamic compressive loading to MSC-seeded constructs and evaluated the resulting changes in construct mechanical properties over 6 weeks of culture. We assessed whether varying pre-culture duration, loading regimens and inclusion of TGF- $\beta 3$ during loading would affect functional outcomes and phenotypic transitions. While long-term loading initiated soon after MSC encapsulation reduced the mechanical properties of constructs, loading initiated after a short period of chondrogenesis and matrix elaboration dramatically improved construct mechanical properties. These findings show, for the first time, that the mechanical properties of MSC-seeded constructs can be enhanced by dynamic compressive loading, and point towards improved clinical translation of MSC-based cartilage constructs.

\section{Materials and Methods}

\section{Mesenchymal stem cell isolation and culture}

Bovine bone marrow derived MSCs were isolated from the tibiae and femurs of 3-6 month old calves (Research 87, MA, USA). Trabecular regions were removed with a saw and agitated in a solution of high glucose Dulbecco's Modified Eagle's Medium (DMEM) supplemented with $2 \%$ penicillin/streptomycin/fungizone (PSF) and $300 \mathrm{U} /$ $\mathrm{mL}$ of heparin. The resulting solution was centrifuged (5 $\mathrm{min}$ at $300 \times \mathrm{g}$ ) and plated onto $10 \mathrm{~cm}$ tissue culture plates. Cultures were expanded in DMEM supplemented with $1 \%$ PSF and 10\% fetal bovine serum (Lot 462819, Gibco (Invitrogen), Carlsbad, CA) with medium changed twice weekly until confluence. Cultures were expanded at a ratio of 1:3 through passage two, and MSCs from at least two donors were combined for each study, with a total of 8 donors used (donor sets A, B, C and D).

\section{Dynamic compression of MSC-seeded constructs}

MSCs were suspended in chemically defined, serum-free medium (CM) and combined 1:1 with sterile type VII agarose $\left(49^{\circ} \mathrm{C}, 4 \% \mathrm{w} / \mathrm{v}\right.$, Sigma, St Louis, MO, USA). Constructs $(\varnothing 4 \mathrm{~mm} \times 2.25 \mathrm{~mm}$ ) were formed with a final cell seeding density of 20 million cells/mL (Huang et al., 2009b). CM consisted of DMEM supplemented with 1X PSF, $0.1 \mu \mathrm{M}$ dexamethasone, $50 \mu \mathrm{g} / \mathrm{mL}$ ascorbate 2phosphate, $40 \mu \mathrm{g} / \mathrm{mL}$ L-proline, $100 \mu \mathrm{g} / \mathrm{mL}$ sodium pyruvate, $6.25 \mu \mathrm{g} / \mathrm{ml}$ insulin, $6.25 \mu \mathrm{g} / \mathrm{ml}$ transferrin, 6.25 $\mathrm{ng} / \mathrm{ml}$ selenous acid, $1.25 \mathrm{mg} / \mathrm{ml}$ bovine serum albumin, and $5.35 \mu \mathrm{g} / \mathrm{ml}$ linoleic acid. For all studies, dynamic unconfined compression was applied using a custom bioreactor with impermeable platens (Fig. 1) (Mauck et al., 2007). The loading protocol consisted of a $10 \%$ dynamic strain superimposed on a static $2 \%$ tare strain, with constructs in unconfined conditions (i.e., allowed to expand radially with axial compression). For all studies, loading was carried out at $37^{\circ} \mathrm{C}$ in a humidified incubator for 5 days per week for 3 weeks with free-swelling controls cultured in parallel. 

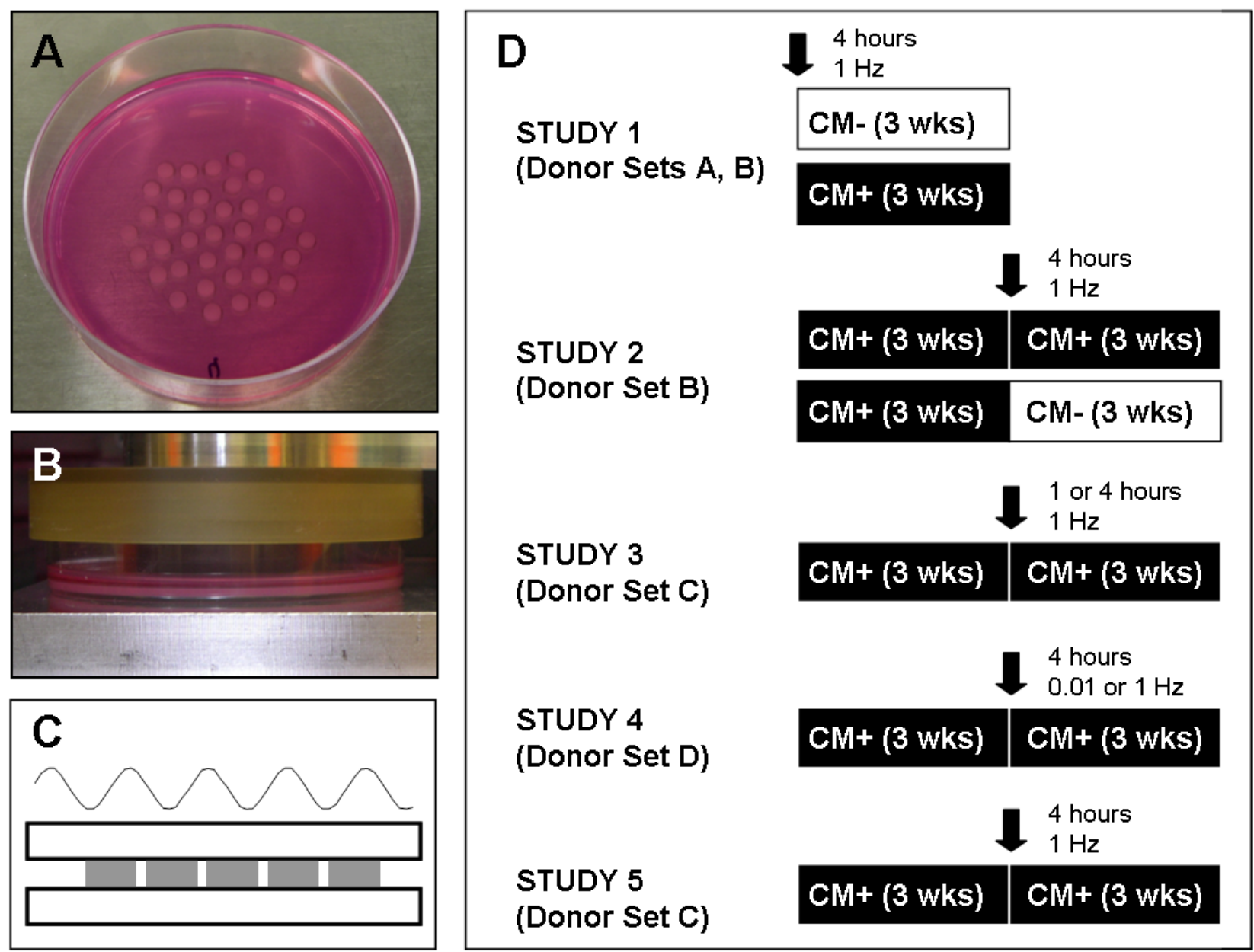

\section{STUDY 3 \\ (Donor Set C)}

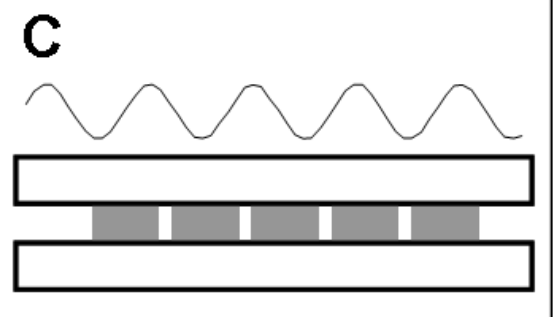

STUDY 4

(Donor Set D)

\section{STUDY 5 \\ (Donor Set C)}

\begin{tabular}{|l|}
4 hours \\
$1 \mathrm{~Hz}$ \\
\hline $\mathrm{CM}-$ (3 wks) \\
\hline $\mathrm{CM}+$ (3 wks) \\
\hline
\end{tabular}

$\mathrm{CM}+(3 \mathrm{wks}) \quad \mathrm{CM}+(3 \mathrm{wks})$

$\mathrm{CM}+(3$ wks) $\mathrm{CM}-(3$ wks)

or 4 hours

$\mathrm{CM}+(3 \mathrm{wks}) \quad \mathrm{CM}+(3 \mathrm{wks})$

4 hours

$\mathrm{CM}+(3 \mathrm{wks}) \quad \mathrm{CM}+(3 \mathrm{wks})$ (A) To hold constructs in place, molds were fabricated by casting a thin layer $(\sim 1.5 \mathrm{~mm}$ thickness $)$ of sterile $4 \%$ agarose; $\varnothing 5 \mathrm{~mm}$ wells were made after gelation and MSC-seeded constructs $(\varnothing 4 \mathrm{~mm})$ were maintained in these wells throughout the culture duration. (B) Impermeable platens were used to apply a (C) sinusoidal displacement to MSC-seeded constructs. (D) Separate studies were carried out to examine the effects of pre-culture, loading duration, loading frequency, and dependence on TGF- $\beta 3$. Arrow indicates timepoint (and conditions) at which loading was initiated.

A total of five independent studies were carried out as outlined in Fig. 1D, with cells combined from two donors for each study (each distinct donor set is indicated accordingly). In Study 1, dynamic compression was initiated 3 days after MSC encapsulation. Loading was applied at $1 \mathrm{~Hz}$ for 4 hours per day in CM supplemented with (CM+) or without (CM-) 10 ng/mL TGF- $\beta 3$ (R\&D Systems, Minneapolis, MN, USA). Gene expression was assessed weekly by real-time PCR. For Studies 2-5, dynamic compression was initiated after a 3 -week preculture period in $\mathrm{CM}+$. In Study 2, pre-cultured constructs were loaded in CM- or $\mathrm{CM}+$ at $1 \mathrm{~Hz}$ for 4 hours per day. In Study 3, loading was applied for 1 hour or 4 hours per day at $1 \mathrm{~Hz}$ in $\mathrm{CM}+$. In Study 4, dynamic compression was applied for 4 hours per day at $1 \mathrm{~Hz}$ or $0.01 \mathrm{~Hz}$ in $\mathrm{CM}+$ medium. In Study 5, free-swelling constructs were cultured in $\mathrm{CM}$ - or $\mathrm{CM}+$ for 6 weeks and loading was applied in $\mathrm{CM}+$ at $1 \mathrm{~Hz}$ for 4 hours daily beginning at week 3 . For all studies, mechanical and biochemical analyses were carried out at 3 and 6 weeks. For Study 5, global gene expression was assessed by microarray.

\section{Mechanical testing of constructs}

To determine mechanical properties, constructs were tested in unconfined compression using a custom testing apparatus (Mauck et al., 2006). Constructs were equilibrated in creep under a static load of two grams for 5 minutes. Following creep deformation, constructs were subjected to $10 \%$ strain applied at $0.05 \%$ /s followed by relaxation for 1000 seconds until equilibrium. Dynamic testing was carried out by applying an additional $1 \%$ sinusoidal deformation to equilibrated constructs at a frequency of $1.0 \mathrm{~Hz}$. The equilibrium and dynamic moduli were determined (Mauck et al., 2006). After mechanical testing, constructs were frozen at $-20^{\circ} \mathrm{C}$ for biochemical evaluation.

\section{Biochemical analysis}

For biochemical analyses, constructs were digested in papain $(0.56 \mathrm{U} / \mathrm{ml}$ in $0.1 \mathrm{M}$ sodium acetate, $10 \mathrm{M}$ cysteine $\mathrm{HCl}, 0.05 \mathrm{M}$ ethylenediaminetetraacetic acid (EDTA), $\mathrm{pH}$ $6.0)$ at $60^{\circ} \mathrm{C}$ for 16 hours. Following digestion, constructs were evaluated for sulfated glycosaminoglycan (GAG) content against a standard curve of chondroitin-6-sulphate 
using the 1,9-dimethylmethylene blue dye-binding assay (Farndale et al., 1986). Collagen content was assessed after acid hydrolysis using the orthohydroxyproline (OHP) assay (Stegemann and Stalder, 1967), with a 1:7.14 OHP:collagen ratio used (Neuman and Logan, 1950). DNA content was determined by means of the PicoGreen dsDNA assay (Molecular Probes, Eugene, OR). GAG and collagen are reported as percentage of construct wet weight while DNA is reported as quantity per construct.

\section{Real time polymerase chain reaction}

Total RNA was extracted by two sequential isolations in TRIZOL-chloroform and quantified (ND-1000, Nanodrop Technologies, Wilmington, DE, USA). Reverse transcription and amplification was carried out using an Applied Biosystems 7300 real-time PCR system with intron spanning primers and SYBR Green Reaction Mix (Applied Biosystems, Foster City, CA, USA) as in (Huang et al., 2009b). For Study 1, collagen type II (COL2A1) and aggrecan (AGC1) expression levels were quantified and normalized to expression of a housekeeping gene (GAPDH).

\section{Microarray hybridization and data analysis}

Total RNA was extracted as described above and quality assessment was performed by the Agilent Bioanalyzer. All protocols were conducted as described in the NuGEN Ovation Manual and the Affymetrix GeneChip Expression Analysis Technical Manual. Briefly, 100 ng of total RNA was converted to first-strand cDNA using reverse transcriptase primed by a poly(T) oligomer that incorporated a synthetic RNA sequence. Following second-strand cDNA synthesis, ribo-SPIA (Single Primer Isothermal Amplification, NuGEN Technologies Inc. San Carlo, CA, USA) was carried out for linear amplification of each transcript and the resulting cDNA was fragmented and biotinylated. $5 \mu \mathrm{g}$ of cDNA was added to hybridization cocktails, heated at $99^{\circ} \mathrm{C}$ for $2 \mathrm{~min}$ and hybridized for 16 $\mathrm{h}$ at $45^{\circ} \mathrm{C}$ to 5 Bovine GeneChips (Affymetrix Inc., Santa Clara, CA, USA). The microarrays were then washed at low (6X SSPE) and high (100 mM MES, 0.1 M NaCl) stringency and stained with streptavidin-phycoerythrin. To amplify fluorescence, biotinylated anti-streptavidin and streptavidin-phycoerythrin stain were added, and fluorescent signals were recorded after excitation at 570 $\mathrm{nm}$ by the Affymetrix Gene Chip Scanner 3000 (Affymetrix).

Output (.cel) files from scanning were processed using Microarray Suite (v.5, Affymetrix) and gene expression was assessed after normalization. Expression levels were evaluated for free-swelling week 6 MSCs in CM-, freeswelling week $6 \mathrm{MSCs}$ in $\mathrm{CM}+$ and week 6 dynamically loaded MSCs in $\mathrm{CM}+$. Microarray data were analyzed using the Spotfire Software (Tibco, Somerville, MA, USA). All microarray data discussed in this manuscript have been deposited in NCBI's Gene Expression Omnibus and are accessible through GEO Series accession number GSE18879 (http://www.ncbi.nlm.nih.gov/geo/query/ acc.cgi? acc $=$ GSE18879).

\section{Histology and immunohistochemistry}

Paraffin sections $(8 \mu \mathrm{m})$ were stained with Hematoxylin and Eosin (H\&E, Sigma,), Alcian Blue (pH 1.0), or Picrosirius Red for cell distribution, sulfated proteoglycans and collagens, respectively. For immunohistochemistry, antigen retrieval was performed by incubating sections in proteinase $\mathrm{K}(20 \mu \mathrm{g} / \mathrm{mL}$ in TE buffer, $\mathrm{pH} 8.0)$ at $37^{\circ} \mathrm{C}$ for 15 minutes, then at $25^{\circ} \mathrm{C}$ for 10 minutes. Collagens type I (MAB3391, Millipore, Billerica, MA) and type II (11116B3, Developmental Studies Hybridoma Bank, Iowa City, IA, USA) primary antibodies were used. Subsequent reaction and visualization with DAB chromagen reagent (DAB150 IHC Select, Millipore) was carried out according to manufacturer's instructions. Color images were captured at $2.5 \mathrm{x}$ or $10 \mathrm{x}$ magnification using a microscope equipped with a color CCD digital camera and the QCapturePro acquisition software.

\section{Fourier transform infrared imaging spectroscopy (FT-IRIS)}

FT-IRIS was carried out using a Spectrum Spotlight 300 spectrometer (Perkin-Elmer, Waltham, MA, USA) equipped with an optical microscope and an array detector. Sections $(8 \mu \mathrm{m})$ were mounted onto barium fluoride windows and scanned with a spatial resolution of $25 \mu \mathrm{m}$ and a spectral resolution of $4 \mathrm{~cm}^{-1}$. The acquired spectra were analyzed using ISys software 5.0 (Malvern Instruments Ltd., Worcestershire, UK). Collagen and proteoglycan distributions were determined by molecular vibrations at specific frequencies (wavenumber, $\mathrm{cm}^{-1}$ ); the amide I absorbance band (1720-1592 $\mathrm{cm}^{-1} ; \mathrm{C}=\mathrm{O}$ stretch) was used to map collagen while proteoglycans were visualized using the $1176-960 \mathrm{~cm}^{-1}$ band (C-O-C and C$\mathrm{OH}$ ring vibrations)(Boskey and Pleshko Camacho, 2007; Kim et al., 2005). FT-IRIS analysis was performed on three samples per group.

\section{Statistical analysis}

Statistics were performed on mechanical and biochemical data using analysis of variance (ANOVA). For Studies 1 and 2, a two way ANOVA was used with media and loading condition as independent variables. For Studies 3-5, a one way ANOVA was carried out. Where significance was indicated by ANOVA, Tukey's posthoc tests were performed. Significance was determined at $p \leq 0.05$ and a trend toward significance determined at $p<0.1$. All values are reported as mean \pm standard deviation.

\section{Results}

\section{Dynamic compression initiated before chondrogenesis impairs functional maturation of MSC-seeded constructs}

To examine the effects of direct mechanical stimulation on functional chondrogenesis, MSC-seeded constructs were subjected to repeated dynamic compression over 3 weeks. In Study 1, dynamic loading (DL) was initiated 3 days after MSC encapsulation and carried out in the 

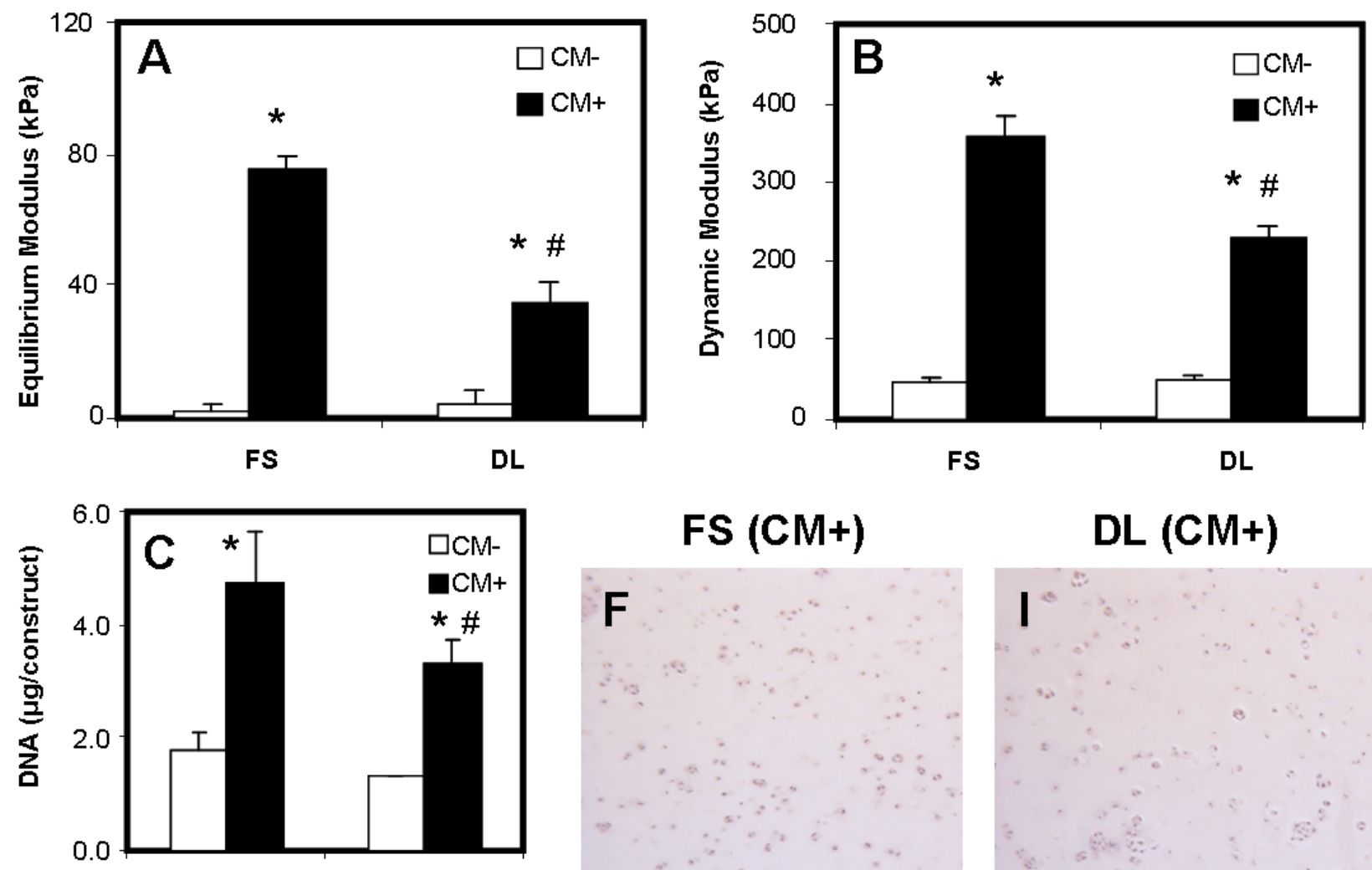

FS (CM+)
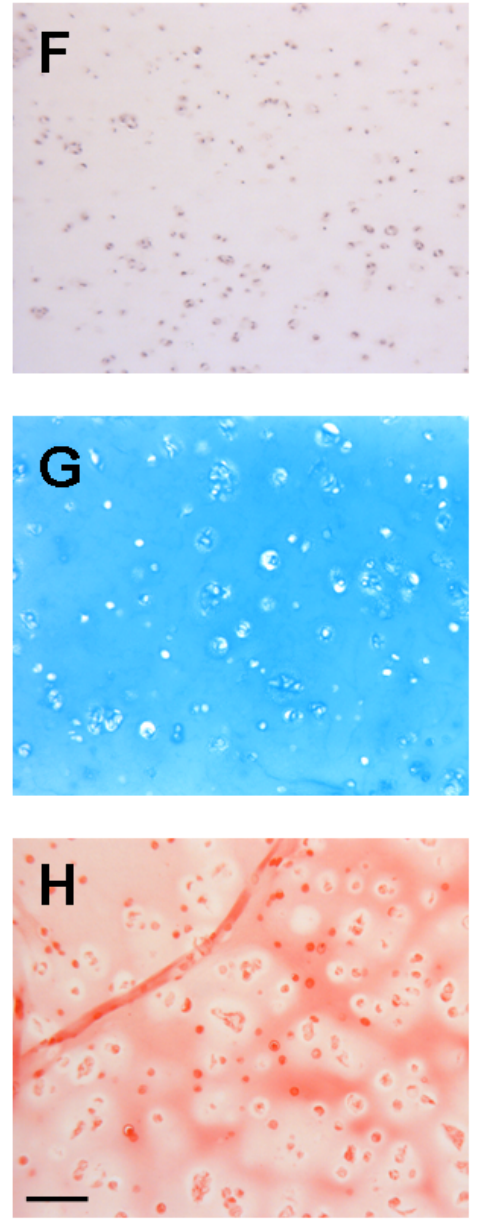

DL (CM+)
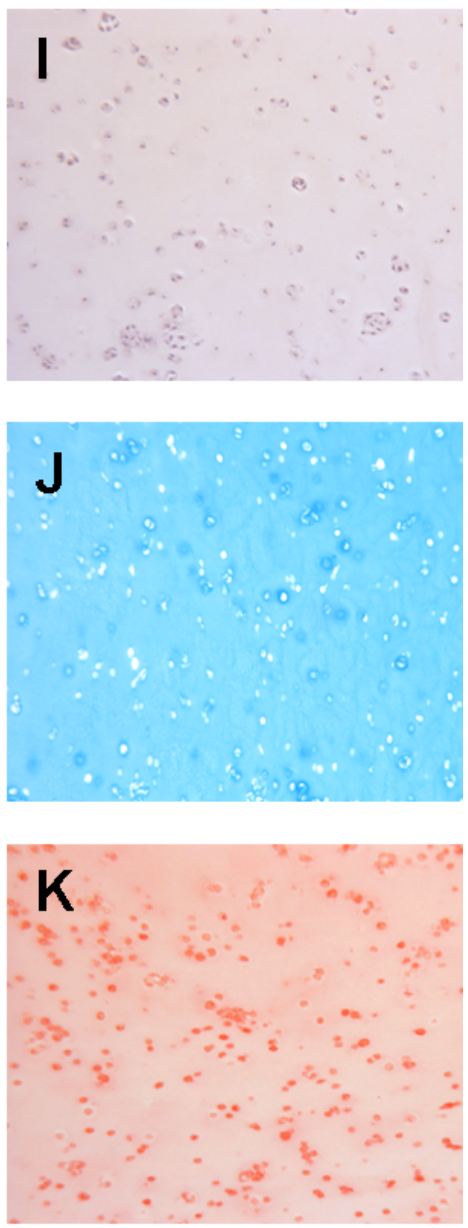

Figure 2: Long-term dynamic compression initiated directly after construct fabrication blocks functional maturation. (A) The equilibrium and (B) dynamic moduli of MSC-seeded constructs loaded in CM+ were impaired by 3 weeks of dynamic compression. (D) DNA, (E) GAG, and (F) collagen contents were similarly modulated. Histological analysis confirmed these findings with (F, I) H\&E, (G, J) Alcian Blue, and (H, K) Picrosirius Red staining for cell content, proteoglycans and collagens, respectively. Scale bar: $100 \mu \mathrm{m}$. * indicates greater than CM- $(p<0.05)$, \# indicates lower than FS CM+ $(p<0.05)$, + indicates lower than FS control within media condition $(p<0.1)$. Data represent the mean and standard deviation of three samples per group per time point. 

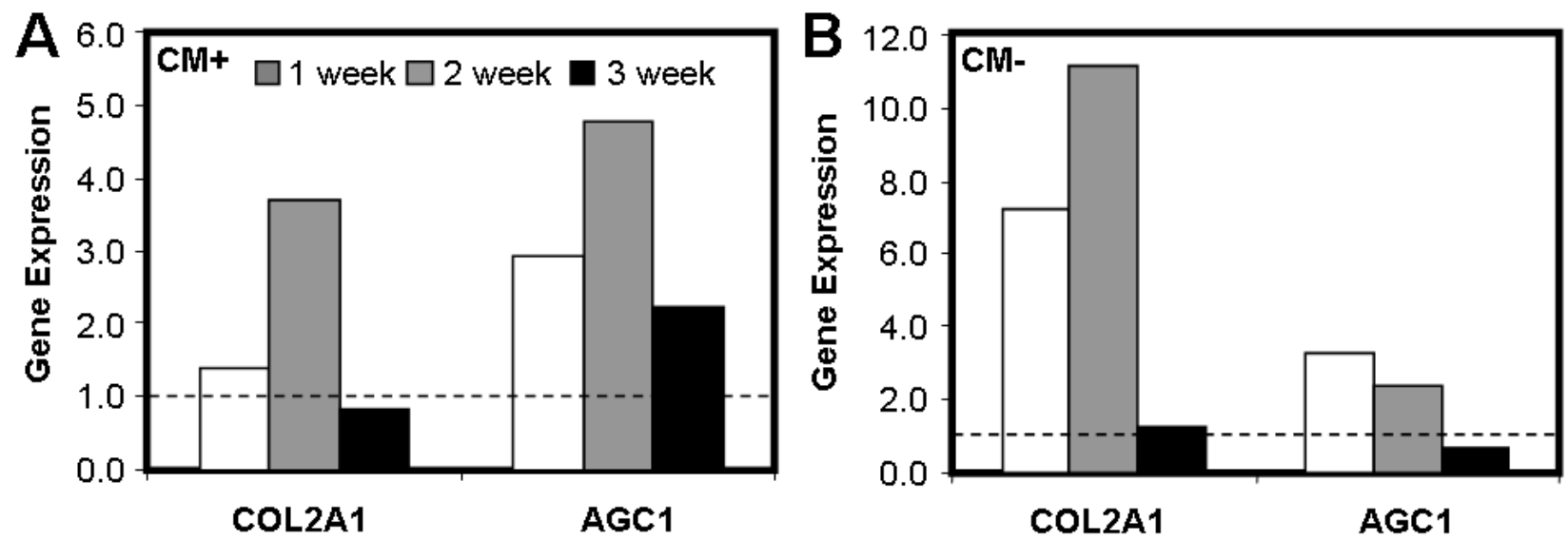

Figure 3: Long-term dynamic compression initiated directly after construct fabrication improves chondrogenic gene expression. After 1 and 2 weeks, COL2A1 and AGC1 expression improved with loading in (A) CM+ and (B) CM- media. Expression levels were normalized to free-swelling controls at each timepoint (indicated by the dashed line).
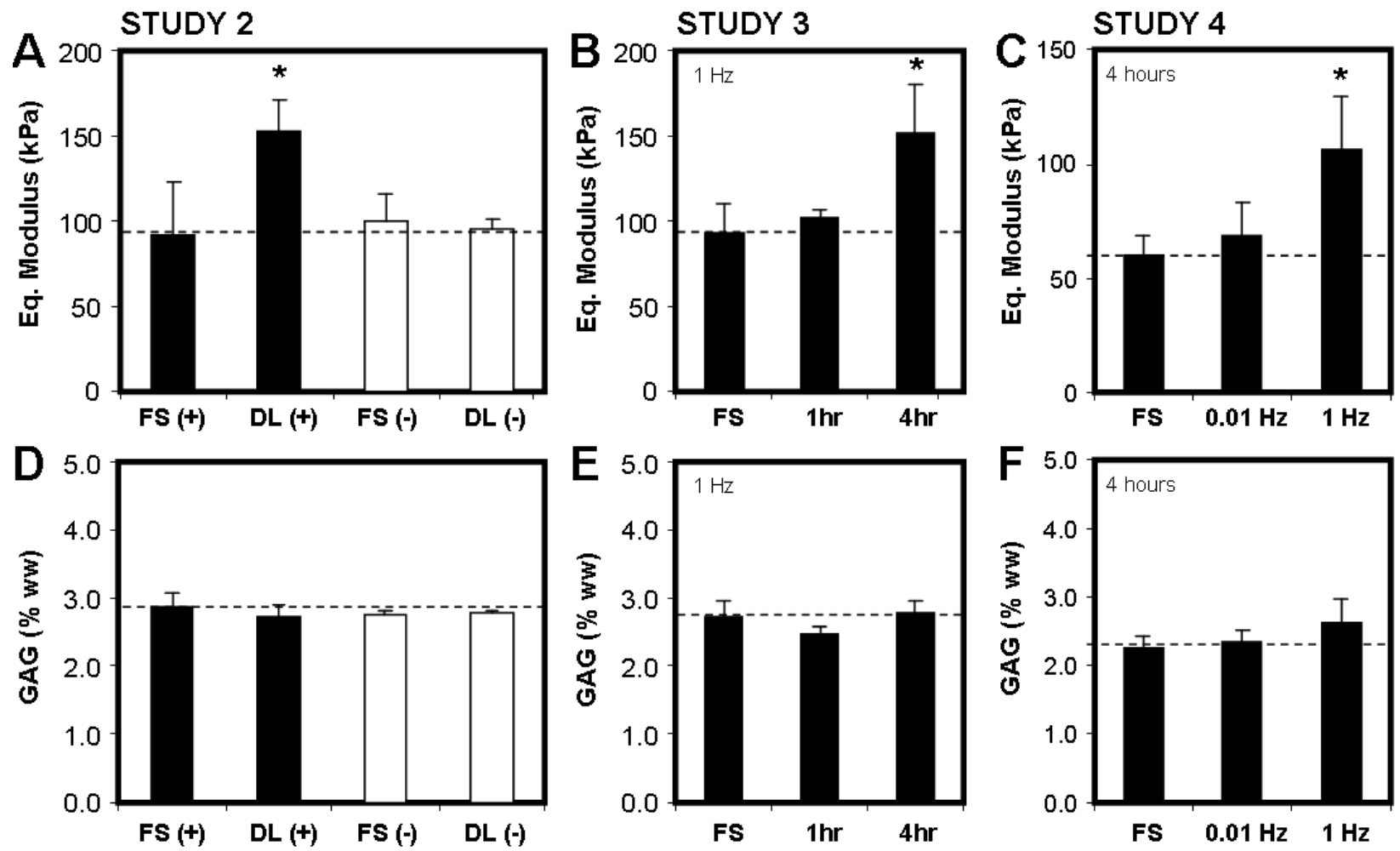

Figure 4: Long-term dynamic loading initiated after 3 weeks of chondrogenic pre-culture improves mechanical properties. (A-C) The equilibrium modulus of MSC-seeded constructs at week 6 improved only when loading was applied in $\mathrm{CM}+$ for 4 hours per day at $1 \mathrm{~Hz}$. No improvement in mechanical properties was observed when other loading regimens were employed. (D-F) GAG content at week 6 was not affected by loading. Black bars indicate $\mathrm{CM}+$ media and white bars indicate CM- media. * indicates greater than control $(p<0.05)$. Data represent the mean and standard deviation of three to five samples per group per time point.

presence $(\mathrm{CM}+)$ or absence $(\mathrm{CM}-)$ of TGF- $\beta 3$. Free swelling (FS) controls were cultured and analyzed identically. The equilibrium and dynamic compressive moduli improved with time in culture for all groups cultured in $\mathrm{CM}+$, regardless of loading $(p<0.05)$. Consistent with our previous studies (Huang et al., 2009b), the equilibrium and dynamic moduli of FS CM+ constructs reached $\sim 80 \mathrm{kPa}$ and $\sim 350 \mathrm{kPa}$, respectively, by 3 weeks. Conversely, the modulus of FS CM- constructs remained similar to that of acellular $2 \%$ agarose ( $2 \mathrm{kPa}$, Fig. $2 \mathrm{~A})$. Long-term DL initiated 3 days after construct fabrication significantly reduced the mechanical properties of $\mathrm{CM}+$ constructs at 3 weeks relative to FS CM+ controls $(p<0.05)$. At 3 weeks, the equilibrium and dynamic moduli of DL $\mathrm{CM}+$ constructs were $\sim 35 \mathrm{kPa}$ and $\sim 230 \mathrm{kPa}$, respectively (Figs. 2A, 2B). Although significantly greater than day 0 properties (equilibrium modulus: $\sim 2 \mathrm{kPa}$, dynamic modulus: $\sim 45 \mathrm{kPa}$ ), these values were less than two thirds that of FS CM+ constructs.

While DL did not change the mechanical properties of CM- constructs (Figs. 2A, 2B), GAG content was reduced with DL (trend, $p=0.07$ ), although DNA and collagen 
STUDY 2

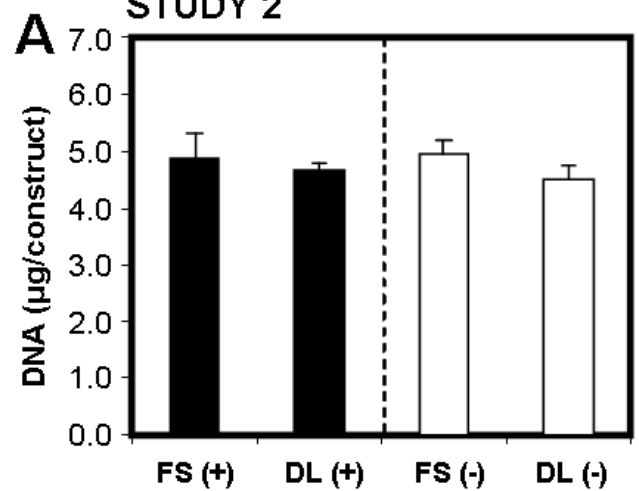

D

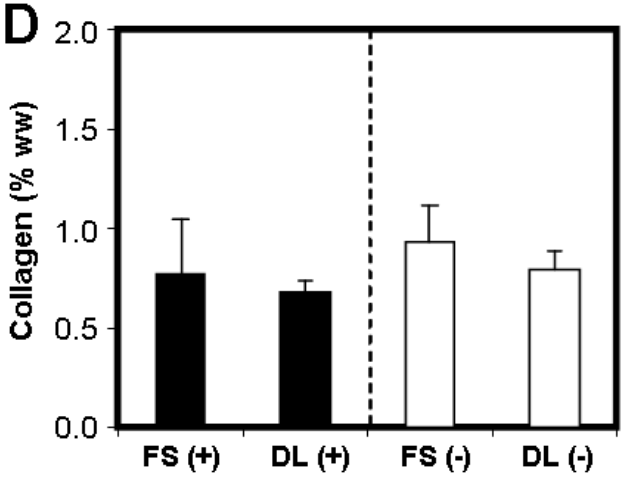

STUDY 3

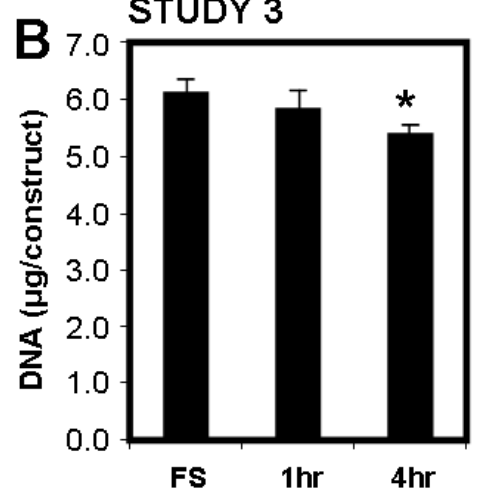

$E$

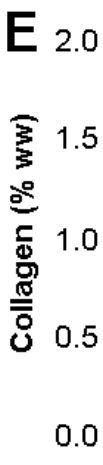

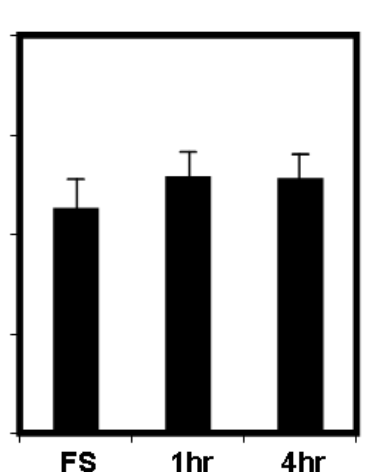

STUDY 4
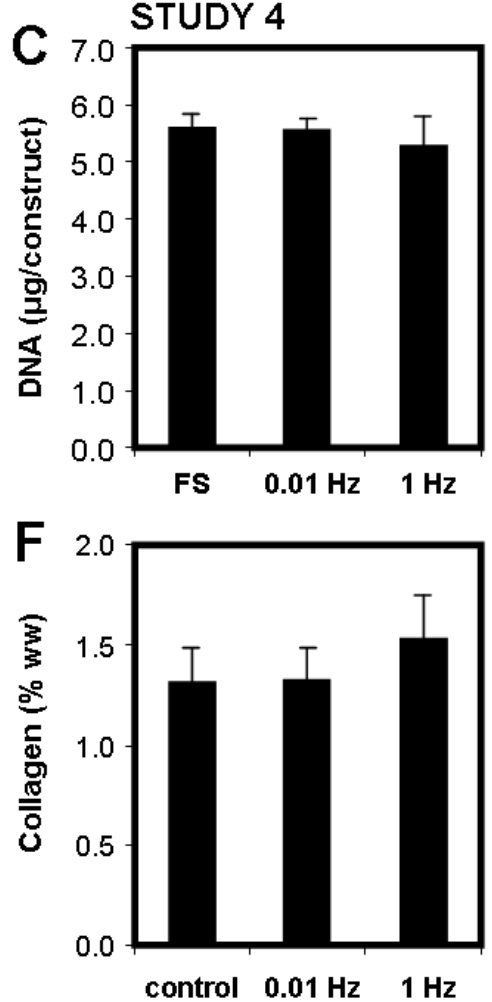

Figure 5: Long-term dynamic loading initiated after 3 weeks of chondrogenic pre-culture does not improve biochemical content. (A-C) The DNA and (D-F) collagen contents of MSC-seeded constructs were largely unchanged with dynamic compressive loading. Black bars indicate $\mathrm{CM}+$ media and white bars indicate $\mathrm{CM}$ - media. * indicates greater than control $(p<0.05)$. Data represent the mean and standard deviation of three to five samples per group per time point.

contents were not affected (Figs. 2C-2E). DL applied in $\mathrm{CM}+$ reduced all biochemical measures relative to $\mathrm{FS}$ $\mathrm{CM}+$. Despite this reduction, DNA and GAG contents remained significantly higher in $\mathrm{DL} \mathrm{CM}+$ compared to either FS CM- or DL CM- groups, indicating that successful chondrogenesis had occurred, but to a lesser extent. DNA content for both FS and DL groups at 3 weeks was also significantly higher than day 3 starting values, while GAG content on a per cell basis (GAG/DNA) was comparable between 3-week FS and DL CM+ groups (not shown). These quantitative biochemical findings were mirrored qualitatively in histological sections, with less intense staining for proteoglycans and collagens observed in DL CM+ compared to FS CM+ sections (Figs. 2F-2K). Real-time PCR analysis of these MSC-seeded constructs showed that while DL reduced mechanical and biochemical measures, DL increased expression of both AGC1 and COL2A1, particularly at weeks 1 and 2 in both CM- and $\mathrm{CM}+$ media relative to FS controls (Fig. 3).

Long-term dynamic compression initiated after chondrogenic pre-culture improves functional properties of MSC-seeded constructs

To assess whether a period of chondrogenic pre-culture alters functional maturation in response to DL, MSCseeded constructs were differentiated in TGF- $\beta 3$ containing media prior to the initiation of loading (Study 2). Constructs were cultured in $\mathrm{CM}+$ for 3 weeks (weeks 1-3) and then subjected to 3 weeks of dynamic loading (weeks 4-6) in $\mathrm{CM}+$ or CM-. As we have previously observed (Huang et al., 2009b), the mechanical properties of MSC-seeded constructs increased with time, but plateaued after 3 weeks with no significant difference in mechanical properties between the 3 and 6 week FS groups in $\mathrm{CM}+$ (not shown). In contrast to Study 1, the equilibrium and dynamic properties of pre-cultured constructs exposed to DL for weeks 4-6 in $\mathrm{CM}+$ were significantly higher than FS controls in $\mathrm{CM}+$ (Fig. 4A). DL CM+ constructs reached equilibrium and dynamic moduli at week 6 of $\sim 150 \mathrm{kPa}$ ( $65 \%$ increase vs. FS CM+) and $\sim 800 \mathrm{kPa}(38 \%$ increase vs. FS CM+), respectively. This increase in properties with DL was only observed when loading was applied in $\mathrm{CM}+$. In the absence of TGF- $\beta 3$ (CM- from week 4 to week 6), DL did not change mechanical properties. To better understand the threshold for DL-induced improvements in functional properties, Studies 3 and 4 examined the influence of loading duration ( 1 or 4 hours) and loading frequency $(0.01$ or $1 \mathrm{~Hz})$ on construct properties. While $\mathrm{DL}$ in $\mathrm{CM}+$ for 4 hours per day at $1 \mathrm{~Hz}$ always increased mechanical properties compared to FS controls, DL for 1 hour per day at $1 \mathrm{~Hz}$ or 4 hours per day at $0.01 \mathrm{~Hz}$ had no effect on these measures (Figs. 4B, 4C).

Despite increases in mechanical properties, GAG (Figs. 4D-4F) and collagen (Fig. 5) contents were not different between any of the CM+ groups. Similarly, GAG released into the media was not different when comparing FS to 
STUDY 5
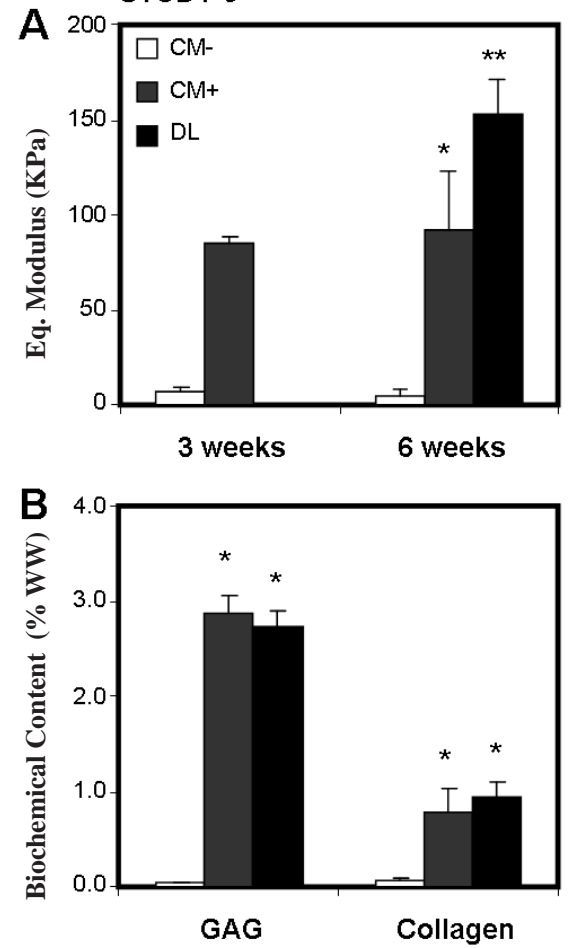

FS (CM-)

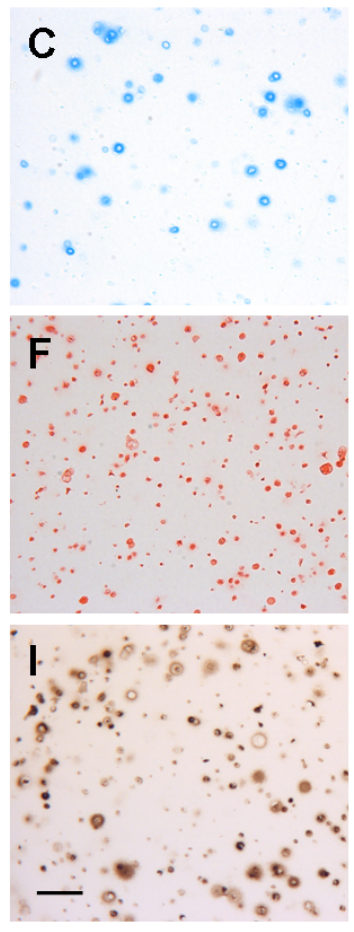

FS (CM+)
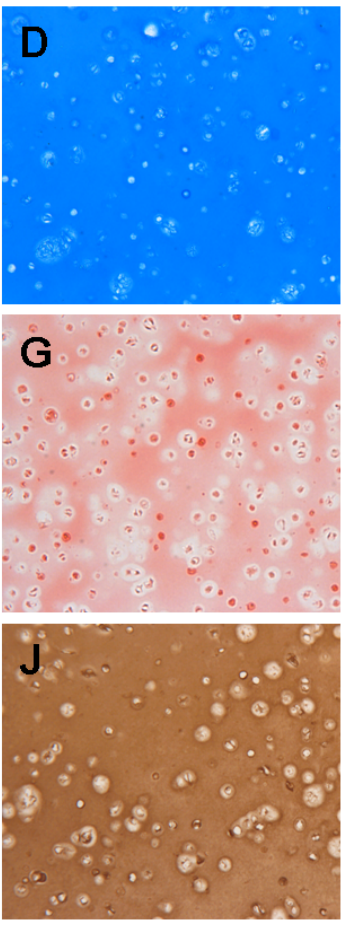

$\mathrm{DL}(\mathrm{CM}+)$
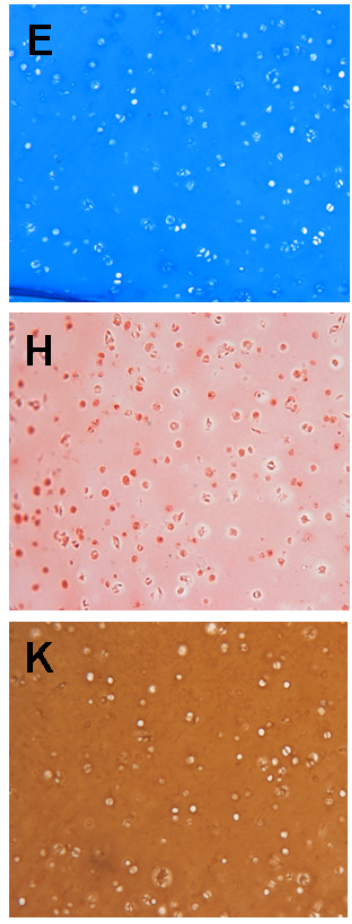

Figure 6: Long-term dynamic loading initiated after 3 weeks of chondrogenic pre-culture improves bulk mechanical properties and microscopic ECM distribution. (A) The equilibrium modulus of MSC-seeded constructs was higher in CM+ compared to CM- at 3 and 6 weeks; dynamic loading in $\mathrm{CM}+$ for 3 weeks further improved mechanical properties. (B) Biochemical content of dynamically loaded constructs at week 6 was not different compared to $\mathrm{CM}+$ controls. (C-E) Alcian Blue staining at week 6 showed equal distribution of proteoglycans between $\mathrm{CM}+$ controls and loaded constructs with weak staining in CM- controls. (F-H) Picrosirius Red staining and (I-K) collagen type II immunostaining showed more homogeneous distribution of collagen in loaded constructs compared to controls, on the microscopic level. Scale bar: $100 \mu \mathrm{m}$. * indicates greater than CM- controls $(p<0.05)$, $* *$ indicates greater than $\mathrm{CM}+$ controls $(p<0.05)$. Data represent the mean and standard deviation of three samples per group per time point.

DL constructs (data not shown). DNA content was not affected by loading in Studies 2 and 4, but was slightly reduced in the 4 hour loaded samples compared to FS conditions in Study 3 (Fig. 5).

\section{Long-term dynamic compression enhances matrix distribution}

Based on Studies 1-4, a dynamic compressive loading protocol of 4 hours per day at a frequency of $1 \mathrm{~Hz}$, initiated after 3 weeks of pre-culture, was applied in a final study designed to further elucidate the mechanism of loadinduced increases in mechanical properties of MSC-seeded constructs (Study 5). As before, loading was carried out for 5 days per week for 3 weeks. Consistent with these previous iterations, the equilibrium modulus improved with DL, but bulk GAG and collagen contents were not different compared to FS (Figs. 6A, 6B). FS CM- constructs did not deposit appreciable ECM with long-term culture; these findings were confirmed histologically with weak pericellular staining for proteoglycans and collagens observed. At the microscopic level, GAG distribution was similar between CM+DL and FS constructs, while collagen content was more uniformly distributed in the $\mathrm{CM}+\mathrm{DL}$ groups (Fig. 6). At the final time point, all $\mathrm{CM}+$ constructs stained strongly for type II collagen (Figs. 6J, 6K) and weakly for type I collagen (Fig. 7), regardless of loading condition. Type II collagen was more uniformly distributed with DL, consistent with the Picrosirius Red stains. Despite the absence of TGF- $\beta 3$, by week 6 , a subset of MSCs in $\mathrm{CM}$ - had undergone chondrogenesis to a limited extent, depositing a small amount of type II collagen in the immediate pericellular space (Fig. 6I). Finally, FT-IRIS was performed as a more sensitive measure of proteoglycan and collagen distribution across the construct expanse. Characteristic spectra for proteoglycans and collagens showed consistently improved distribution with DL, particularly in the construct central regions (Fig. 8).

\section{Expression profiles with chondrogenic induction and long term dynamic compression}

In a final analysis, a preliminary microarray screen was performed to visualize shifts in molecular topography that might underlie the observed differences in mechanical properties with dynamic loading. This screen compared whole genome expression profiles for week 6 FS CMsamples, FS CM+ samples, and DL CM+ samples. CMand $\mathrm{CM}+\mathrm{FS}$ groups were chosen as undifferentiated and differentiated controls, respectively, in order to identify 
FS (CM-)

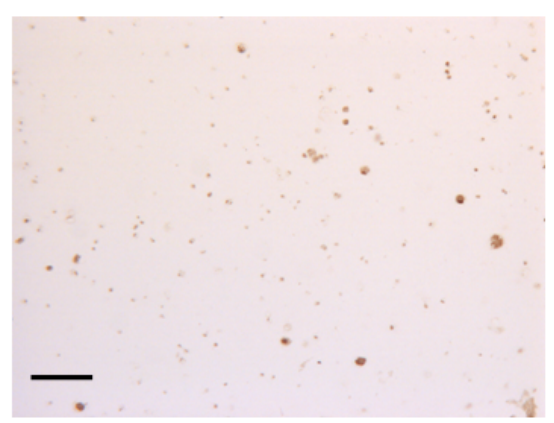

FS (CM+)

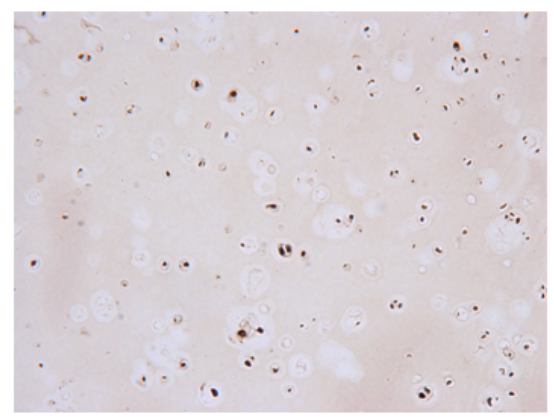

$\mathrm{DL}(\mathrm{CM}+)$

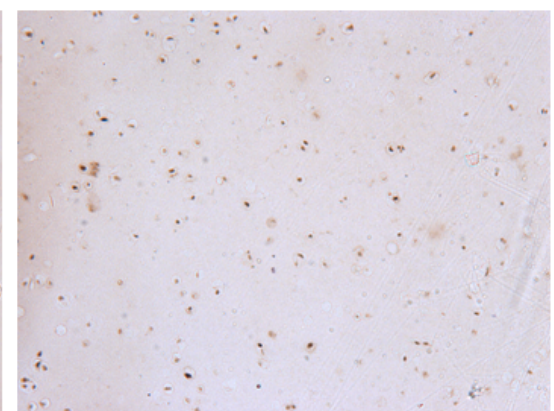

Figure 7: Type I collagen staining of free-swelling and dynamically loaded constructs at week 6. Weak, pericellular staining for type I collagen was observed for all constructs, regardless of loading. Scale bar: $100 \mu \mathrm{m}$.

\section{Control $(\mathrm{CM}+)$}

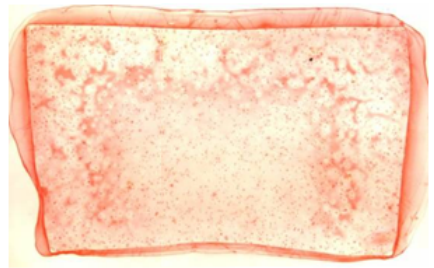

Alcian

Blue

Collagen

\section{Picrosirius Red}

Proteoglycan

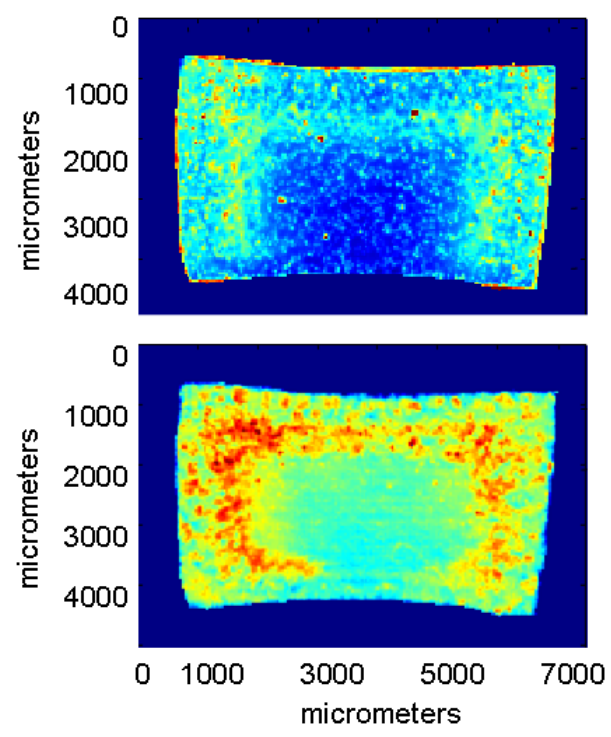

DL (CM+)
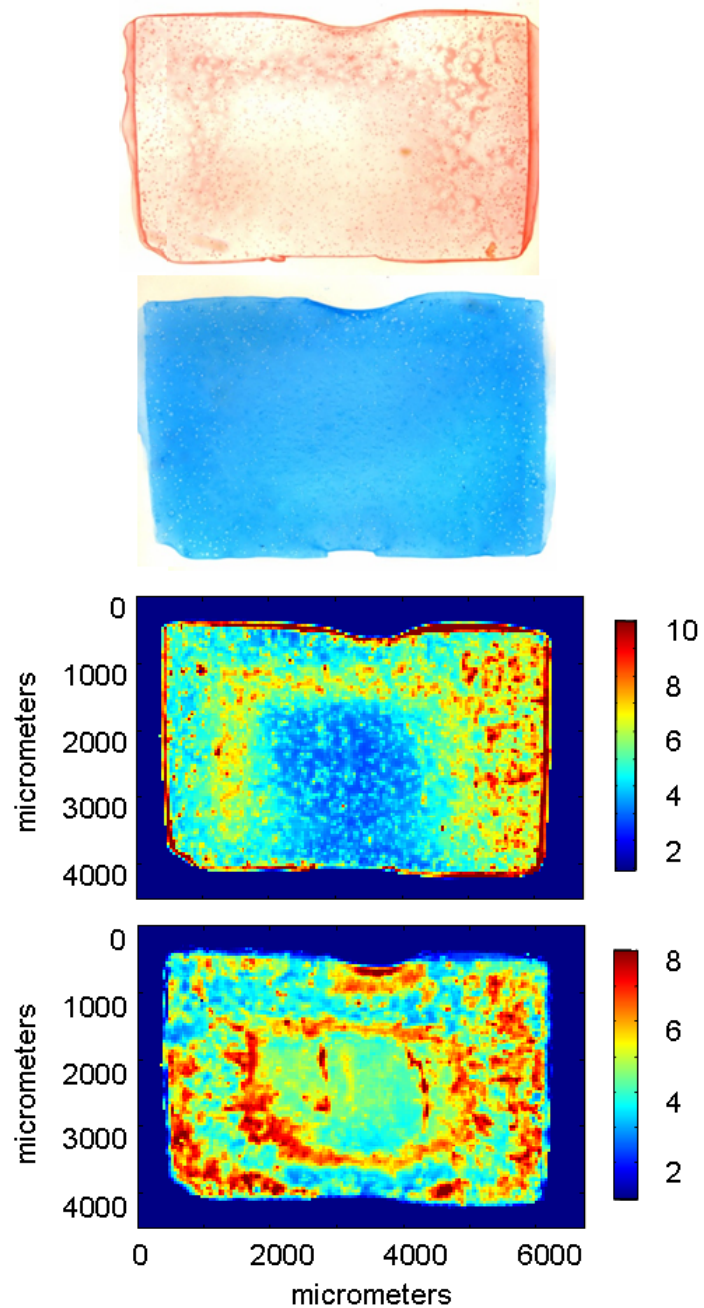

Figure 8: FT-IRIS assessment of matrix distribution at 6 weeks. Whole construct views of Picrosirius Red and Alcian Blue stained cross-sections showing distributions of collagen and proteoglycan within FS and DL constructs. Spectral data obtained from FT-IRIS analysis, a more sensitive and semi-quantitative measurement technique, showed improved collagen and proteoglycan distribution within MSC-seeded constructs with dynamic compressive loading. Scale bar: $1 \mathrm{~mm}$. 


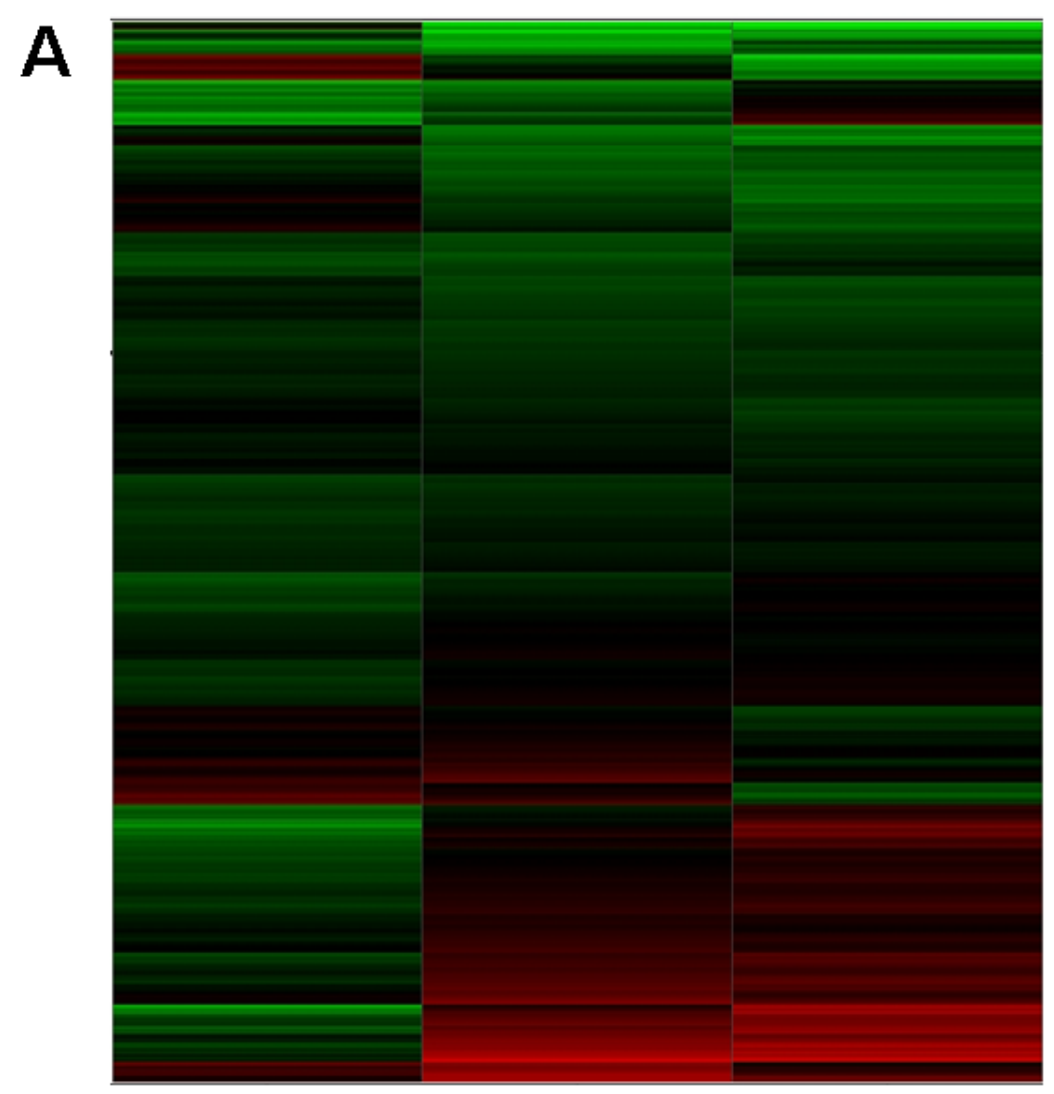

$\mathrm{DL}$ vs $\mathrm{CM}+\quad \mathrm{DL}$ vs $\mathrm{CM}-\quad \mathrm{CM}+$ vs $\mathrm{CM}-$

\section{B Greater Than (3-fold)}

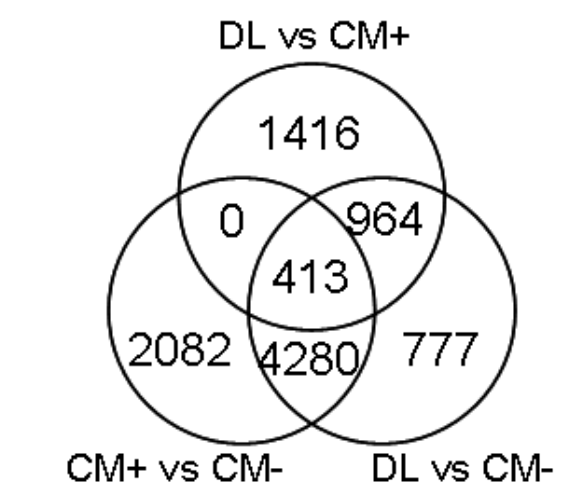

C Lower Than (3-fold)

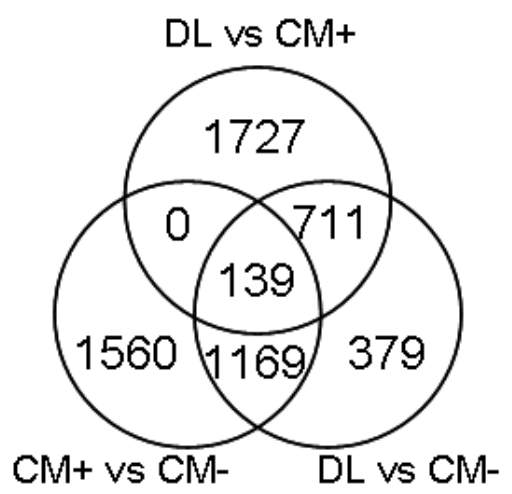

Figure 9: Molecular topography of chondro-induction and mechanosensitivity. (A) Heat map generated from microarray data showing differential gene expression (red = greater, green = lower) between CM- free-swelling (FS) controls (CM-), CM+ FS controls (CM+) and constructs dynamically loaded (DL) in CM+ at day 42. (B, C) Venn diagrams indicate a number of genes that are differentially regulated with chondrogenic induction $(\mathrm{CM}+)$ in $3 \mathrm{D}$ culture and with dynamic compressive loading ( $>3$-fold).

Tables: These two tables are available separately as supplementary files and can be downloaded from the website (http://www.ecmjournal.org/journal/papers/vol019/vol019a08.php).

Table 1: (18 pages) Complete list of genes that were up-regulated ( $>3$-fold) at week 6 with dynamic compressive loading compared to $\mathrm{CM}+$ free-swelling control.

Table 2: (22 pages) Complete list of genes that were down-regulated ( $>3$-fold) at week 6 with dynamic compressive loading compared to CM+ free-swelling control.

\section{Discussion}

markers associated with functional chondrogenesis. Heat maps at week 6 showed changes in gene expression with chondrogenesis (CM+vs. CM-), with higher and lower levels of expression for individual genes depicted in red and green, respectively (Fig. 9A). While the molecular fingerprints between FS CM+ and DL $\mathrm{CM}+$ were more alike compared to FS CM-, DL modulated the expression of a number of genes (Fig. 9A). Venn diagrams showed 5449 genes that were chondrogenic, but not mechanically sensitive; of these genes, 4280 were up-regulated and 1169 were down-regulated during chondrogenesis (Figs. 9B, 9C). In addition, numerous genes associated with chondrogenesis were further modulated by DL (413 upregulated, 139 down-regulated). A complete list of the genes modulated by DL can be found in Tables 1 and 2 .
Mesenchymal stem cells (MSCs) are an ideal candidate for cartilage tissue engineering given their ability to undergo chondrogenesis in 3D culture. Under prochondrogenic conditions, MSCs deposit a cartilagespecific matrix and accrue increasingly robust mechanical properties with time. However, recent findings suggest that further optimization may be required to generate properties akin to that of the native tissue, or that of articular chondrocytes cultured similarly (Huang et al., 2009b; Mauck et al., 2006). As mechanical stimulation plays a unique role in both cartilage development and the maturation of chondrocyte-based engineered constructs, we examined long-term dynamic compressive loading as a means of modulating MSC-seeded construct properties and chondrogenesis 
Consistent with previous findings, long-term dynamic loading initiated soon after MSC encapsulation in the presence of TGF- $\beta 3$ reduced the mechanical properties of constructs compared to free-swelling controls (Thorpe et al., 2008). While biochemical content was lower in these dynamically loaded samples, GAG content per cell was not different from controls and chondrogenic gene expression was up-regulated with loading at each time point assayed. As loading did not affect cell viability, these data suggest that long-term loading in the presence of TGF$\beta 3$ reduced MSC proliferation with commensurate decreases in bulk biochemical and mechanical properties, but did not impair chondrogenic differentiation. Dynamic compression alone, in the absence of TGF- $\beta 3$, failed to induce chondrogenesis; in fact, after three weeks of loading, GAG content decreased in loaded groups, though chondrogenic gene expression increased. Thus, while longterm dynamic compression, initiated prior to cell differentiation or matrix deposition, may improve the expression of AGC1 and COL2A1, mechanical properties and GAG content are inferior in these samples, regardless of TGF- $\beta$ supplementation. Whether this lower GAG content in loaded constructs is due to poor retention of synthesized GAG (caused by differences in molecule size/ assembly or possible upregulation of catabolic agents) or due to an actual reduction in GAG synthesis is currently unclear.

In contrast to these findings, loading initiated after chondrogenesis and matrix elaboration in the presence of TGF- $\beta 3$ consistently improved the mechanical properties of MSC-seeded constructs. As all other factors remained constant, the timing of load initiation was crucial in determining functional outcomes. These divergent responses to loading can be attributed to changes in MSC phenotype and construct properties with maturation. Work in ligament tissue engineering support the notion that the timing of mechanical stimulation with MSC developmental stage may be a critical determinant of cell response to load (Chen et al., 2006). Similarly, dynamic compression applied after an extended pre-culture time improved chondrogenic gene expression of MSCs, as well as embryonic stem cells (Mouw et al., 2007; Terraciano et al., 2007). As the nuclei of undifferentiated stem cells deform more readily than that of differentiated cells (Pajerowski et al., 2007), the differentiation status of MSCs may play an important role in how these cells perceive external mechanical stimulation. Cell-matrix interactions may also affect load-induced response; since agarose is an inert material, these interactions emerge only as MSCs differentiate and generate local ECM. With matrix elaboration, the physical environment of the cells under dynamic compression is also altered. As construct composition shifts from $2 \%$ agarose to a denser, cartilagelike matrix of proteoglycans and collagen and construct permeability decreases, the stresses induced by dynamic compression are higher and largely borne through fluid pressurization (Soltz and Ateshian, 1998); this is apparent from our mechanical testing results showing marked increases in the dynamic modulus with culture duration. These differences in fluid pressurization and fluid flow may underlie the profoundly disparate outcomes we observe with dynamic compressive loading, depending on construct maturity. This is consistent with several studies showing that application of hydrostatic pressure to human MSC aggregates improves cartilaginous matrix deposition and gene expression (Angele et al., 2003; Miyanishi et al., 2006).

Interestingly, in the absence of TGF- $\beta 3$, compressive loading initiated after chondrogenic pre-culture did not elicit any changes in functional properties, indicating that the load-induced increase in mechanics is dependent on TGF- $\beta 3$. This is consistent with previous findings showing improved matrix synthesis and $\mathrm{pSmad} 2 / 3$ protein levels in pre-cultured bovine MSC-seeded agarose with a single application of loading, when loading was applied in the presence of TGF- $\beta 1$ and dexamethasone (Mouw et al., 2007). In contrast to MSCs, repeated dynamic compression of pre-cultured chondrocyte-seeded agarose improved the mechanical properties of these constructs when loading was applied in the absence of TGF- $\beta 3$ (Lima et al., 2007). Long-term dynamic compression initiated prior to matrix elaboration also improved the functional properties of chondrocyte-based constructs, though these studies were conducted in the presence of serum (Mauck et al., 2000). Collectively, these studies suggest that the mechanotransduction pathways initiated by dynamic compression may be fundamentally different between chondrocytes and undifferentiated or chondrogenically differentiated MSCs and underscores the need for better characterization of these cell types relative to one another.

While it is unclear how dynamic compression may improve functional MSC chondrogenesis, one potential mechanism may be facilitated nutrient/growth factor transport with dynamic deformation. Theoretical models of dynamic compression of porous permeable materials indicate that solute transport into constructs may be improved by dynamic loading and that higher frequencies enhance this phenomenon (Mauck et al., 2003b). Recent experimental findings validate these theoretical predictions and show that, in particular, the transport of large solutes (with molecular weights similar to that of growth factors such as TGF- $\beta$ ) is facilitated by dynamic compression and is dependent on loading duration (Albro et al., 2008; Chahine et al., 2009). In one set of experiments with acellular agarose gels of varying concentrations, solute uptake increased for higher concentration gels (Albro et al., 2008). These results parallel findings from the current study, where mechanical properties only increased when dynamic loading was initiated after pre-elaboration of matrix (denser construct), and applied at longer durations (4 hours vs. 1 hour) at a higher frequency (1 Hz vs. 0.01 $\mathrm{Hz}$ ). Notably, loading in the absence of exogenous TGF$\beta 3$ (after chondrogenic pre-culture) failed to elicit any changes in mechanical properties.

Although enhanced transport of nutrients or TGF- $\beta$ is one possible mechanism, MSC responsivity to mechanical stimulus may also be an important factor. To assess MSC response on the molecular level, we carried out microarray analysis of loaded and free-swelling constructs and saw marked overlap in chondrogenic gene expression, indicating successful induction and stability of the chondrogenic phenotype. Consistent with these findings, 
all constructs stained strongly for collagen type II and weakly for collagen type I. As bulk GAG and collagen contents were not affected by loading (despite increases in mechanical properties), minor elements involved in matrix remodeling and refinement may be of consequence. Though preliminary, microarray analysis indicated modulation of several genes from the MMP/TIMP family, as well as specialized cross-linking molecules. Additional analyses will be necessary to validate these findings and determine the potential role of these genes under dynamic compression. Although measurement of gene expression is not necessarily a reliable predictor of functional chondrogenesis (i.e., Study 1), evidence for matrix remodeling was found by histology and FT-IRIS. These analyses showed improved matrix distribution after 3 weeks of repeated loading. Histological stains showed better pericellular distribution of collagen and FT-IRIS showed enhanced macroscopic distribution of proteoglycans and collagens throughout the construct expanse. This is consistent with previous studies of chondrocyte-based constructs showing improved collagen organization (assessed by polarized light microscopy) with dynamic compressive loading (Kelly et al., 2006).

To our knowledge, this is the first study to demonstrate improved mechanical properties of MSC-based engineered cartilage through the long-term application of dynamic compressive loading. While the mechanism underlying these increased properties is not yet established, we show that improved matrix distribution, suggestive of matrix remodeling and refinement occurs with dynamic compression. Although we achieved a $\sim 65 \%$ improvement in mechanical properties over 3 weeks of loading, these values remain lower than native cartilage. Future studies will optimize these parameters over longer culture durations to further explicate load-induced increases in mechanical properties. We will also evaluate MMP activity and the expression and distribution of minor elements indicated from microarray analysis, as well as assess proteoglycan size and collagen crosslinking with dynamic loading. The use of other biomaterials, including materials that mimic the native ECM or materials that include hydrolytic or MMP-cleavable components to allow better matrix distribution, may also aid matrix remodeling and further enhance functional outcomes (Erickson et al., 2009a; Chung et al., 2009; Park et al., 2004; Lutolf et al., 2003). The combination of these tunable materials with our optimized loading regime will generate clinicallyrelevant, mechanically robust MSC-based constructs for articular cartilage repair.

\section{Acknowledgements}

This work was supported by the National Institutes of Health (EB008722, AR053668), the Penn Center for Musculoskeletal Disorders (P30 AR050950) and a Graduate Research Fellowship from the National Science Foundation (AHH). The type II collagen antibody developed by Thomas F. Linsenmayer was obtained from the Developmental Studies Hybridoma Bank developed under the auspices of the NICHD and maintained by the University of Iowa, Department of Biology, Iowa City, IA 52242, USA. The authors also gratefully acknowledge the Penn Microarray Core Facility and Dr. Don Baldwin for their help with microarray processing, Dr. George Dodge for helpful discussions, and the Mineralized Tissue Laboratory at the Hospital for Special Surgery and Lyudmila Spevak for their help with FT-IRIS analysis (core facility supported by NIH grant AR046121).

\section{References}

Albro MB, Chahine NO, Li R, Yeager K, Hung CT, Ateshian GA (2008) Dynamic loading of deformable porous media can induce active solute transport. J Biomech 41: 3152-3157.

Angele P, Yoo JU, Smith C, Mansour J, Jepsen KJ, Nerlich M, Johnstone B (2003) Cyclic hydrostatic pressure enhances the chondrogenic phenotype of human mesenchymal progenitor cells differentiated in vitro. J Orthop Res 21: 451-457.

Angele P, Schumann D, Angele M, Kinner B, Englert C, Hente R, Fuchtmeier B, Nerlich M, Neumann C, Kujat $R$ (2004) Cyclic, mechanical compression enhances chondrogenesis of mesenchymal progenitor cells in tissue engineering scaffolds. Biorheology 41: 335-346.

Boskey A, Pleshko Camacho N (2007) FT-IR imaging of native and tissue-engineered bone and cartilage. Biomaterials 28: 2465-2478.

Chahine NO, Albro MB, Lima EG, Wei VI, Dubois CR, Hung CT, Ateshian GA (2009) Effect of dynamic loading on the transport of solutes into agarose hydrogels. Biophys J 97: 968-975.

Chen J, Horan RL, Bramono D, Moreau JE, Wang Y, Geuss LR, Collette AL, Volloch V, Altman GH (2006) Monitoring mesenchymal stromal cell developmental stage to apply on-time mechanical stimulation for ligament tissue engineering. Tissue Eng 12: 3085-3095.

Chen X, Macica CM, Nasiri A, Broadus AE (2008) Regulation of articular chondrocyte proliferation and differentiation by indian hedgehog and parathyroid hormone-related protein in mice. Arthritis Rheum 58: 3788-3797.

Chung C, Burdick JA (2009) Influence of threedimensional hyaluronic acid microenvironments on mesenchymal stem cell chondrogenesis. Tissue Eng Part A 15: 243-254.

Chung C, Beecham M, Mauck RL, Burdick JA (2009) The Influence of degradation characteristics of hyaluronic acid hydrogels on in vitro neocartilage formation by mesenchymal stem cells. Biomaterials 30: 4287-4296.

Elder SH (2002) Conditioned medium of mechanically compressed chick limb bud cells promotes chondrocyte differentiation. J Orthop Sci 7: 538-543.

Elder SH, Kimura JH, Soslowsky LJ, Lavagnino M, Goldstein SA (2000) Effect of compressive loading on chondrocyte differentiation in agarose cultures of chick limb-bud cells. J Orthop Res 18: 78-86.

Elder SH, Goldstein SA, Kimura JH, Soslowsky LJ, Spengler DM (2001) Chondrocyte differentiation is 
modulated by frequency and duration of cyclic compressive loading. Ann Biomed Eng 29: 476-482.

Erickson IE, Huang AH, Chung C, Li RT, Burdick JA, Mauck RL (2009a) Differential maturation and structurefunction relationships in mesenchymal stem cell- and chondrocyte-seeded hydrogels. Tissue Eng Part A 15: 1041-1052.

Erickson IE, Huang AH, Sengupta S, Kestle S, Burdick JA, Mauck RL (2009b) Macromer density influences mesenchymal stem cell chondrogenesis and maturation in photocrosslinked hyaluronic acid hydrogels. Osteoarthritis Cartilage 17: 1639-1648.

Farndale RW, Buttle DJ, Barrett AJ (1986) Improved quantitation and discrimination of sulphated glycosaminoglycans by use of dimethylmethylene blue. Biochim Biophys Acta 883: 173-177.

Hofmann S, Knecht S, Langer R, Kaplan DL, VunjakNovakovic G, Merkle HP, Meinel L (2006) Cartilage-like tissue engineering using silk scaffolds and mesenchymal stem cells. Tissue Eng 12: 2729-2738.

Huang AH, Farrell MJ, Mauck RL (2009a) Mechanics and mechanobiology of mesenchymal stem cell-based engineered cartilage. J Biomech 43: 128-136.

Huang AH, Stein A, Tuan RS, Mauck RL (2009b) Transient exposure to TGF-beta3 improves the mechanical properties of MSC-laden cartilage constructs in a density dependent manner. Tissue Eng Part A 15: 3461-3472.

Huang CY, Hagar KL, Frost LE, Sun Y, Cheung HS (2004) Effects of cyclic compressive loading on chondrogenesis of rabbit bone-marrow derived mesenchymal stem cells. Stem Cells 22: 313-323.

Huang CY, Reuben PM, Cheung HS (2005) Temporal expression patterns and corresponding protein inductions of early responsive genes in rabbit bone marrow-derived mesenchymal stem cells under cyclic compressive loading. Stem Cells 23: 1113-1121.

Johnstone B, Hering TM, Caplan AI, Goldberg VM, Yoo JU (1998) In vitro chondrogenesis of bone marrowderived mesenchymal progenitor cells. Exp Cell Res 238: 265-272.

Kavalkovich KW, Boynton RE, Murphy JM, Barry F (2002) Chondrogenic differentiation of human mesenchymal stem cells within an alginate layer culture system. In Vitro Cell Dev Biol Anim 38: 457-466.

Kelly TA, Ng KW, Wang CC, Ateshian GA, Hung CT (2006) Spatial and temporal development of chondrocyteseeded agarose constructs in free-swelling and dynamically loaded cultures. J Biomech 39: 1489-1497.

Kim M, Bi X, Horton WE, Spencer RG, Camacho NP (2005) Fourier transform infrared imaging spectroscopic analysis of tissue engineered cartilage: histologic and biochemical correlations. J Biomed Opt 10: 031105.

Kisiday J, Frisbie DD, McIlwraith W, Grodzinsky A (2009) Dynamic compression stimulates proteoglycan synthesis by mesenchymal stem cells in the absence of chondrogenic cytokines. Tissue Eng Part A 15: 2817-2824.

Li WJ, Tuli R, Okafor C, Derfoul A, Danielson KG, Hall DJ, Tuan RS (2005) A three-dimensional nanofibrous scaffold for cartilage tissue engineering using human mesenchymal stem cells. Biomaterials 26: 599-609.
Lima EG, Bian L, Mauck RL, Byers BA, Tuan RS, Ateshian GA, Hung CT (2006) The effect of applied compressive loading on tissue-engineered cartilage constructs cultured with TGF-beta3. Conf Proc IEEE Eng Med Biol Soc 1: 779-782.

Lima EG, Bian L, Ng KW, Mauck RL, Byers BA, Tuan RS, Ateshian GA, Hung CT (2007) The beneficial effect of delayed compressive loading on tissue-engineered cartilage constructs cultured with TGF- $\beta 3$. Osteoarthritis Cartilage 15: 1025-1033.

Lutolf MP, Lauer-Fields JL, Schmoekel HG, Metters AT, Weber FE, Fields GB, Hubbell JA (2003) Synthetic matrix metalloproteinase-sensitive hydrogels for the conduction of tissue regeneration: engineering cellinvasion characteristics. Proc Natl Acad Sci U S A 100: 5413-5418.

Mauck RL, Soltz MA, Wang CC, Wong DD, Chao PH, Valhmu WB, Hung CT, Ateshian GA (2000) Functional tissue engineering of articular cartilage through dynamic loading of chondrocyte-seeded agarose gels. J Biomech Eng 122: 252-260.

Mauck RL, Wang CC, Oswald ES, Ateshian GA, Hung CT (2003a) The role of cell seeding density and nutrient supply for articular cartilage tissue engineering with deformational loading. Osteoarthritis Cartilage 11: 879890.

Mauck RL, Hung CT, Ateshian GA (2003b) Modeling of neutral solute transport in a dynamically loaded porous permeable gel: implications for articular cartilage biosynthesis and tissue engineering. J Biomech Eng 125: 602-614.

Mauck RL, Yuan X, Tuan RS (2006) Chondrogenic differentiation and functional maturation of bovine mesenchymal stem cells in long-term agarose culture. Osteoarthritis Cartilage 14: 179-189.

Mauck RL, Byers BA, Yuan X, Tuan RS (2007) Regulation of cartilaginous ECM gene transcription by chondrocytes and MSCs in $3 \mathrm{D}$ culture in response to dynamic loading. Biomech Model Mechanobiol 6: 113125.

Miyanishi K, Trindade MC, Lindsey DP, Beaupre GS, Carter DR, Goodman SB, Schurman DJ, Smith RL (2006) Effects of hydrostatic pressure and transforming growth factor-beta 3 on adult human mesenchymal stem cell chondrogenesis in vitro. Tissue Eng 12: 1419-1428.

Mikic B, Johnson TL, Chhabra AB, Schalet BJ, Wong M, Hunziker EB (2000) Differential effects of embryonic immobilization on the development of fibrocartilaginous skeletal elements. J Rehabil Res Dev 37: 127-133.

Mikic B, Isenstein AL, Chhabra A (2004) Mechanical modulation of cartilage structure and function during embryogenesis in the chick. Ann Biomed Eng 32: 18-25.

Mouw JK, Connelly JT, Wilson CG, Michael KE, Levenston ME (2007) Dynamic compression regulates the expression and synthesis of chondrocyte-specific matrix molecules in bone marrow stromal cells. Stem Cells 25: 655-663.

Neuman RE, Logan MA (1950) The determination of hydroxyproline. J Biol Chem 184: 299-306. 
Pajerowski JD, Dahl KN, Zhong FL, Sammak PJ, Discher DE (2007) Physical plasticity of the nucleus in stem cell differentiation. Proc Natl Acad Sci U S A 104: 15619-15624.

Park Y, Lutolf MP, Hubbell JA, Hunziker EB, Wong M (2004) Bovine primary chondrocyte culture in synthetic matrix metalloproteinase-sensitive poly(ethylene glycol)based hydrogels as a scaffold for cartilage repair. Tissue Eng 10: 515-522.

Pittenger MF, Mackay AM, Beck SC, Jaiswal RK, Douglas R, Mosca JD, Moorman MA, Simonetti DW, Craig S, Marshak DR (1999) Multilineage potential of adult human mesenchymal stem cells. Science 284: 143147.

Prockop DJ (1997) Marrow stromal cells as stem cells for nonhematopoietic tissues. Science 276: 71-74.

Soltz MA, Ateshian GA (1998) Experimental verification and theoretical prediction of cartilage interstitial fluid pressurization at an impermeable contact interface in confined compression. J Biomech 31: 927934.

Stegemann H, Stalder K (1967) Determination of hydroxyproline. Clin Chim Acta 18: 267-273.
Terraciano V, Hwang N, Moroni L, Park HB, Zhang Z, Mizrahi J, Seliktar D, Elisseeff J (2007) Differential Response of Adult and Embryonic Mesenchymal Progenitor Cells to Mechanical Compression in Hydrogels. Stem Cells.

Thorpe SD, Buckley CT, Vinardell T, O'Brien FJ, Campbell VA, Kelly DJ (2008) Dynamic compression can inhibit chondrogenesis of mesenchymal stem cells. Biochem Biophys Res Commun 377: 458-462.

Williamson AK, Chen AC, Sah RL (2001) Compressive properties and function-composition relationships of developing bovine articular cartilage. J Orthop Res 19: 1113-1121.

Williamson AK, Chen AC, Masuda K, Thonar EJ, Sah RL (2003a) Tensile mechanical properties of bovine articular cartilage: variations with growth and relationships to collagen network components. J Orthop Res 21: 872880 .

Williamson AK, Masuda K, Thonar EJ, Sah RL (2003b) Growth of immature articular cartilage in vitro: correlated variation in tensile biomechanical and collagen network properties. Tissue Eng 9: 625-634. 